\title{
Assessment of Water Quality using Fuzzy-AHP and TOPSIS
}

\author{
Asmita Sonavane $\mathrm{e}^{1,{ }^{*}, \text { Devyani Narkhede }}{ }^{2}$, Shruti Pawar $^{3}$ and Tabassum Maktum ${ }^{4}$ \\ 1,2,3,4Ramrao Adik Institute of Technology, Nerul, Navi Mumbai, Maharashtra, India.
}

\begin{abstract}
The quality of water available to people has deteriorated because of the vast increase in global industries. The overall quality of water has reduced due to the high use of fertilizers in farms and chemicals in sectors such as mining and construction. The quality of water has a direct impact on the health of humans and hence it is necessary to evaluate the quality of drinking water. The quality of water is dependent on various substances like $\mathrm{pH}$, ammonia, iron, arsenic etc. present in water. If these parameters are available in an appropriate amount in water then only the water is considered as of good quality. The problem of assessing water quality is usually considered as multi-criteria decision problem. In this paper an approach to evaluate quality of water using Fuzzy Analytical Hierarchical Process (Fuzzy-AHP) and Technique for Order Preference by Similarity to Ideal Solution (TOPSIS) is proposed. The parameters which are considered for evaluation include Arsenic, Ammonia, Iron, Nitrate, Dissolved Oxygen and Ph. The relative importance of these parameters is utilized while applying the Fuzzy-AHP process and weights for each parameter are computed. The various datasets containing values for considered parameters are collected and the weights are used to assign quality levels to these water samples. The paper also gives the performance analysis of the proposed method in terms of accuracy. The accuracy is measured in terms of how many water samples are assigned correct quality level and the results show that the proposed method has better accuracy as compared to traditional AHP and Fuzzy- AHP method.
\end{abstract}

Keywords- Water Quality, AHP, Fuzzy-AHP, Standard Error Calculation, GWQI, MCDM, TOPSIS, BWM TOPSIS

\section{Introduction}

Water covers 70 percent of our planet, and it's simple to assume that it'll continually be quite sufficient. However, freshwater that's used for drinking purposes, bathing, and irrigating farm fields is rare. World's 3 percent of water is fresh whereas the $2 / 3$ percent of it is frozen glaciers and the left part is unprocurable for usage relating to human health, due to lack of sanitation as well as the dearth of potable water. Natural Phenomena like Erosion and other industrial activities like accidents and urban sprawl cause Water Pollution [1]. Whereas, they also embody threats through exposure to pathogens from chemical toxicants as well as organic occurrences. For example, the irrigation by contaminated water or bioaccumulation of ototoxic chemicals by aquatic animals throughout swimming in contaminated water. [2]. Therefore, in Life and Trade the highest priority is the interception of pollution.

A system that would check the accuracy of necessary elements in water is required so water quality is analyzed.
The project proposes a technique to identify water quality on basis of various parameters, as, arsenic, ammonia, iron, nitrate, dissolved oxygen and $\mathrm{Ph}$.

Potable water with low levels of arsenic over an extended period is associated with polygenic disorder and raised risk of cancers of organs in excretory and urinary system specifically. It additionally causes skin issues, such as development of corns, lesions and also discoloration of skin [3]. So, the acceptable range of water is below $0.010 \mathrm{ppm}$ [4].

Ammonia is toxic to aquatic animals at concentration less than 1ppm in water as it leads to toxic build up in internal tissues and blood, and potentially death [5]. Human beings are least affected by ammonia in potable water, but if water with more than $1 \mathrm{ppm}$ ammonia is ingested for a longer period then it may damage the internal organ system [6].

Iron is not hazardous to health, but it is considered a secondary or aesthetic contaminant because iron can carry bacteria in drinking water. High concentration of iron in

\footnotetext{
* Corresponding author: asmitass0403@gmail.com
} 
water gives a yellow, reddish orange, or brownish look. Iron causes your water to taste metallic as well as affect the taste of foods cooked and also blackens vegetables and absorbs the metallic taste [7]. Therefore, the acceptable range for iron in water is less than $0.3 \mathrm{mg} / 1[8]$.

The Nitrate cannot be tasted, smelled, or seen in water. Consuming too much nitrate can affect the blood which carries oxygen and can be especially harmful for babies. If there is an excess level of nitrates, plants and algae will grow excessively whereas if we drink water that is high in nitrates it will intervene the ability of RBC's to transport oxygen[9].The acceptable range for nitrate in water is less than or equal to $10 \mathrm{ppm}[10]$.

Dissolved oxygen is the most important parameter of water quality as most aquatic organisms need oxygen to survive and grow. When dissolved oxygen becomes too low aquatic organisms cannot survive. Also, it affects human health [11]. Therefore, the acceptable range required is between 6.5 to $8 \mathrm{mg} / \mathrm{l}$ [12].

$\mathrm{Ph}$ is important in body to keep balance as well as to synchronize metabolic processes. Here as, a diet with high $\mathrm{pH}$ causes weight gain and the immune reactions also become slow whereas an alkaline diet causes an inability to make sync with key nutrients in body. Therefore, water with more free hydrogen ions in water indicates it is acidic, whereas more free hydroxyl ions in water indicates it is basic [13]. $\mathrm{pH}$ is measured on a scale of $0-14$ and the acceptable range is 6.5 to $8.5[14]$.

In this paper a design and development of a system for monitoring of the water quality is presented. The proposed system will help people in water redundant areas to detect the quality of water. Water resources in remote villages get contaminated due to numerous reasons, thus the proposed system will help to tell if particular water is drinkable or not.

The major contributions of the paper are as follows:

1. To monitor the quality of water on the basis of different parameters such as Arsenic, Ammonia, Iron, Nitrate, Dissolved Oxygen and $\mathrm{Ph}$.

2. To find relative importance among the considered parameters by applying AHP, FuzzyAHP and TOPSIS Method.

3. To assign different quality levels to the considered water samples.

4. To compare performance of the proposed method with different datasets of water samples.

5. To achieve the optimal solution for water quality analysis using TOPSIS.

This research paper is organized as follows:

Section 1 is Introduction which gives the techniques and information of the various parameters to identify water quality. Section 2 is Related Work which gives the survey of existing systems to tell how people all over the world are trying to solve the problem of scarcity of clean drinking water by developing various real time water quality monitoring systems. Section 3 demonstrates the Proposed System in which the system design of the proposed method is presented. Finally, the Conclusion and Future Work is expounded in Section 5.

\section{Related Work}

In An Giang the Northeast and the Southeast regions have bad quality water due to high Arsenic amount in water caused in monsoon season due to sediment deposition. Whereas, it also has bad ground water quality due to the combined effect of human and natural activities $[2,15]$. In areas, wherever groundwater is extracted for irrigation it had high values of GWQI links with high Arsenic content. Hence, Fuzzy AHP was successfully applied based upon GWQI for assessing ground water quality in An Giang.

The eight wells in An Giang have improved their groundwater quality from 2009 to 2018 within the monsoonal season as collated to other seasons. As this is because during wet season there is a decrease in deposition of small solid particles near the flood plains which lessens the river discharge. Therefore, there is a reduction in the movement of pollutants in water by filling of unused wells for them to be groundwater aquifers. There is no sufficient evidence to show that there is a relation between Arsenic and Sediment Deposition at present.

The Vietnamese Mekong Delta (VMD) of An Giang the secondary canals have a high amount of nutrients and that's why people rely on it as the sources underneath the land function are the most important supplies not only for domestic usages but partially for irrigation as well and it also release the rice intensifications of untreated agricultural efflux. Hence, the Water Quality mostly exceeds the Vietnamese standards for domestic water system.

Water bodies portray an important role in the construction business, day-to-day life, farming irrigation and fire protection in the ecological surroundings. China's rapid development in economy has resulted in increased water pollution which indirectly resulted in forming a compounded water scarcity problem thus becoming an obstacle for the country's growth and modernism. Hence, a case study was conducted on six regions in North China and further the integrated Fuzzy BWM-TOPSIS method was applied.

The unsuitable use Groundwater may be a significant issue as the rapidly increasing population and also the expansion of social economy has incremented the utilization of water resources [15]. Due to which there is a disparity between accessible water and demanded water in few areas. Simultaneously, Groundwater Pollution is also there due to the obvious downturn of groundwater levels, Therefore, the water resources also do not satisfy the basic water-use standards due to which there is also decrement in the ecosystem services.

The Qing 'an Country is being focused for a case study which aspires to progress an improved Fuzzy AHP method to allot water rights to corporations. Also, an evaluation index system has been accepted for the assigning of initial water rights and has also subsumed physical geography, economic, and ecological standard. This system gets categorized into four parts [15]. Here, Fuzzy AHP method helps to determine the order of 
priority of the evaluation index and the total weight of initial water rights for different corporations. Assigned initial water rights got ranked in the descending order of their total weights coefficient according to the results observed.

\section{Proposed Work}

In the proposed system the six parameters are considered for evaluating water quality such as, Arsenic, Ammonia, Iron, Nitrate, Dissolved Oxygen, $\mathrm{pH}$. The proposed architecture contains a generation of pairwise comparison matrix, weight calculation, score generation and assigning quality levels. The system involves weight calculation using MCDM methods namely Fuzzy AHP and AHP. Then the TOPSIS algorithm is applied to assign quality levels such as excellent, good, bad or unsuitable.

In 1981, Hwang and Yoon firstly proposed TOPSIS whereas in 1992, Chen and Hwang developed it.The TOPSIS method calculates the distance between the best scheme and the worst scheme in the continuous time series of samples and use the relative degree of the ideal solution as the standard of comprehensive evaluation.

TOPSIS detects the optimal solution as well as the distance of worst solution for sorting. Whereas for being optimal the evaluation object should be close to the optimal solution and as distant as possible compared to worst solution otherwise it cannot be optimal.

Therefore, Technique for Order Preference by Similarity to Ideal Solution (TOPSIS) is at present one of the most approved MCDM methods and also used in various application areas such as manufacturing, industries as well as government sectors [16].

The pairwise comparison matrix is computed to decide priority among the considered parameters. This matrix is further utilized by the AHP and Fuzzy-AHP algorithm and weight for each parameter is computed. Finally the score is generated for the weighted parameters using the weighted sum method. Then the quality levels are assigned to the samples respectively.

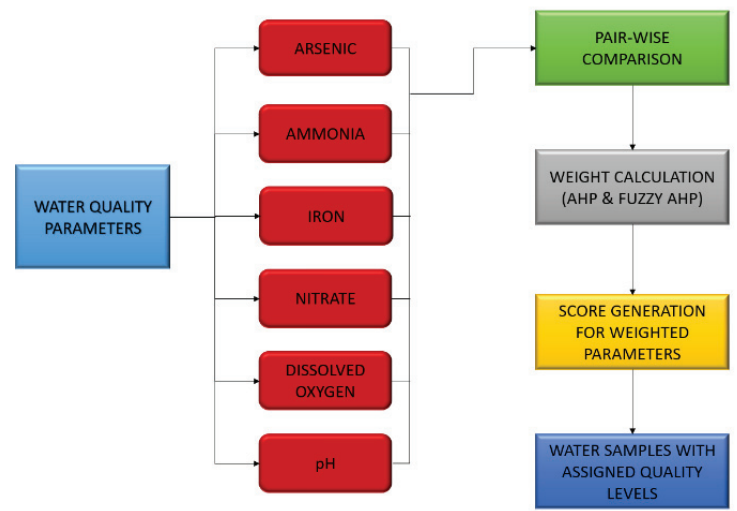

Fig. 1. System Design of AHP \& Fuzzy AHP

The entire process is explained in following steps:

1 Develop pair-wise comparison matrix for $n$ parameters as $\mathrm{M}_{\mathrm{nxn}}$ with the help of scale of relative importance.
2 Conversion of crisp numeric values to Fuzzy numbers associated with triangular membership function.

If crisp value is $\mathrm{n}$ then fuzzification is done by the formula $(\mathrm{n}-1, \mathrm{n}, \mathrm{n}+1)$ except at 1 and 9 where the Fuzzy numbers associated will be $(1,1,1)$ and $(9,9,9)$. If crisp value is $1 / \mathrm{n}$ then Fuzzy number is of the form $\left(\frac{1}{n+1}, \frac{1}{n}, \frac{1}{n-1}\right)$.

3 Calculate the Row-wise Multiplications of all the Fuzzy numbers, where the calculated number is $(\mathrm{x}, \mathrm{y}, \mathrm{z})$.

Formulae for the multiplication and addition of Fuzzy numbers:

$$
\begin{aligned}
& \left(l_{1}, m_{1}, u_{1}\right) \otimes\left(l_{2}, m_{2}, u_{2}\right) \\
& =\left(l_{1} * l_{2}, m_{1 * m_{2}}, u_{1} * u_{2}\right) \\
& \left(l_{1}, m_{1}, u_{1}\right) \oplus\left(l_{2}, m_{2}, u_{2}\right)=\left(l_{1}+\right. \\
& \left.l_{2}, m_{1}+m_{2}, u_{1}+u_{2}\right)
\end{aligned}
$$

4 Calculation of Fuzzy geometric mean value

$r_{\mathrm{i}}$, where $r_{\mathrm{i}}$ for each attribute in matrix $\mathrm{M}$ is $r_{\mathrm{i}}=$ (pow $(\mathrm{x}, 1 / n)$, pow $(\mathrm{y}, 1 / n)$, pow $(\mathrm{z}, 1 / n)$ )

5 Calculation of the Fuzzy weights $\left(w_{\mathrm{i}}\right)$

Where,

$$
w_{\mathrm{i}}=r_{\mathrm{i}} \otimes\left(r_{1} \oplus r_{2} \ldots \oplus \oplus r_{\mathrm{n}}\right)^{-1}
$$

6 Defuzzify the Fuzzy weights to get the crisp weights $\left(W_{\mathrm{i}}\right)$ by using the Defuzzification method 'Centre Of Area'(COA).

$$
W_{\mathrm{i}}=\frac{a+b+c}{3}
$$

Where, $(\mathrm{a}, \mathrm{b}, \mathrm{c})$ is the Fuzzy weight $\left(w_{\mathrm{i}}\right)$.

7 Generate the score as

$$
\begin{aligned}
& \text { Score }=\sum_{i=1}^{n} \mathrm{~W}_{\mathrm{i}}^{*} p_{\mathrm{i}} \\
& \text { Where, } \\
& \mathrm{W}_{\mathrm{i}}=\text { Normalized weight } \\
& p_{\mathrm{i}}=\text { Normalized Parameter value }
\end{aligned}
$$

The weight parameters are calculated using above steps 1 to 7, now following process is used to assign Quality Levels to water sample.

8 The Normalized Matrix is calculated using,

$$
r_{i j}=\frac{X_{i j}}{\sqrt{\sum_{i=1}^{n} X_{i j}^{2}}}
$$

Where,

$\mathrm{X}_{\mathrm{IJ}}=$ Parameter value

9 The Weighted Normalized Matrix is calculated as

$$
v_{i j}=r_{i j} * W_{j}
$$

Where,

$$
\mathrm{i}=1,2, \ldots \mathrm{n} ; \mathrm{j}=1,2, \ldots, \mathrm{m}
$$

Then the Calculation of the Ideal best $v_{j}^{+}$and Ideal worst values $v_{j}^{-}$using $v_{i j}$ is done.

10 Next is the calculation of the Euclidian distance from the ideal best $S_{i}^{+}$and the ideal worst $S_{i}^{-}$. 


$$
\begin{aligned}
& S_{i}^{+}=\left[\sum_{j=1}^{m}\left(v_{i j}-v_{j}^{+}\right)^{2}\right]^{0.5} \\
& S_{i}^{-}=\left[\sum_{j=1}^{m}\left(v_{i j}-v_{j}^{-}\right)^{2}\right]^{0.5}
\end{aligned}
$$

11 After this, calculate the performance Score $P_{i}$,

$$
P_{i}=\frac{S_{i}^{-}}{S_{i}^{+}+S_{i}^{-}}
$$

12 If $\mathrm{P}_{\mathrm{i}}>=0.8$ then level $\mathrm{i}_{\mathrm{i}}=$ Excellent Else if $0.6<\mathrm{P}_{\mathrm{i}}>=0.8$ then level $\mathrm{i}_{\mathrm{i}}=$ Good Else if $0.3<=\mathrm{P}_{\mathrm{i}}<=0.6$ then level $_{\mathrm{i}}=\mathrm{Bad}$ Else level $\mathrm{i}_{\mathrm{i}}=$ Unsuitable

\section{Results \& Discussion}

In this paper the method is implemented to assign quality levels for different water samples. The prototype of proposed method is implemented in java with a minimum hardware configuration of core i3 processor and 4GB RAM. The different datasets with varying numbers of water samples are considered. These samples include the amount of Arsenic, Ammonia, Iron, Nitrate, Dissolved Oxygen, $\mathrm{pH}$ present in water. The five different datasets with 100, 200, 300, 400 and 500 samples are considered. The values of all these parameters are collected from [17$20]$. The value of each parameter is normalized to range [0-1] by applying min-max normalization method. The proposed method assigns a quality level as excellent, good, bad, unsuitable to water samples. In order to assign quality levels to water samples the weights must be assigned to the considered parameters. The weights are calculated using AHP and fuzzy- AHP algorithms. The weighted sum method is utilized to assign a final score to the water sample. The method to assign quality level to water samples by applying TOPSIS method is also implemented. If the final score is found to be greater than or equal to 0.8 , the water quality is considered to be excellent, if it is found to be in between 0.6 and 0.8 then quality of water is good. If the final score is between 0.3 and 0.6 then the level assigned will be bad and if it is below 0.3 the water quality level will be unsuitable.

In Figure 2 the comparison of Standard Error while assigning quality levels for water is presented, the three methods such as Fuzzy AHP, TOPSIS with Fuzzy AHP weights are considered for this comparison. The accuracy of each method is measured in terms of Standard Error. The smaller Standard Error value indicates more accuracy. It can be observed from the Figure 2 that the error is more for Fuzzy AHP method as compared to TOPSIS method for all datasets. The error for TOPSIS with AHP and Fuzzy AHP weights are almost similar. For increased number of Samples also, the Standard Error value for TOPSIS with Fuzzy AHP weights remains smaller than the Fuzzy AHP method. Thus, the proposed method with TOPSIS and Fuzzy AHP weights assigns quality levels to water samples more accurately and hence it is an appropriate method for calculating quality levels.

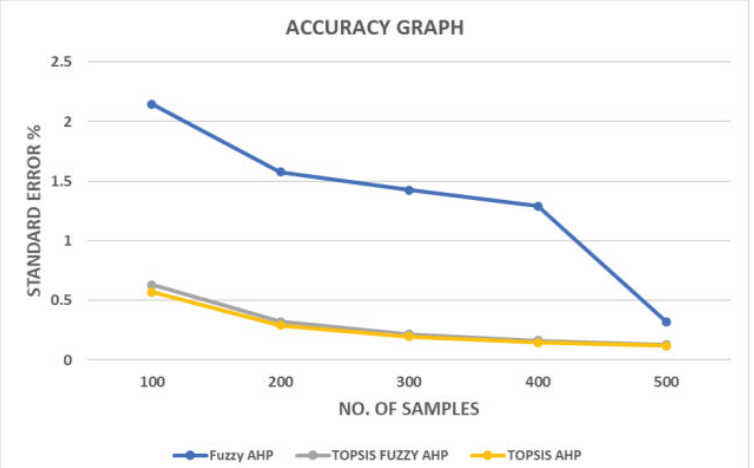

Fig. 2. Comparison of Standard Error with respect to No. of Samples

In Figure 3 the comparison of Mean Execution Time is presented for two methods such as TOPSIS with Fuzzy AHP weights and standard Fuzzy AHP method. The different datasets with varying numbers of water samples are considered. The mean execution time of each method is measured in terms of time in seconds which indicates time required for execution. The mean value of ten executions of each algorithm is considered for comparison. Hence, we can conclude that the execution speed of both algorithms is almost similar for all the datasets.

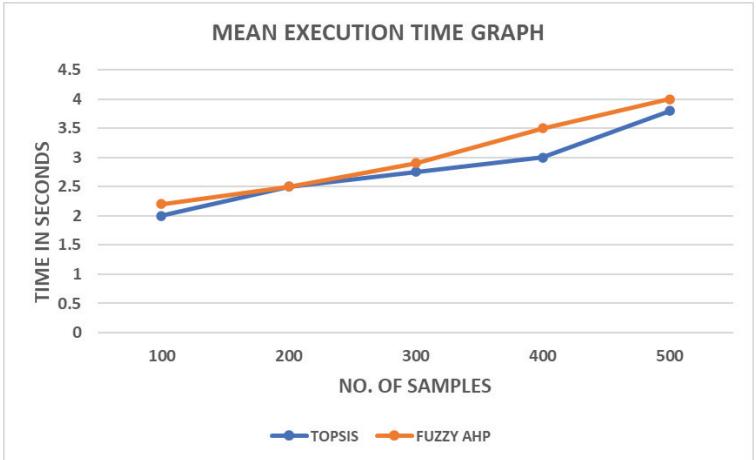

Fig. 3. Comparison of Mean Execution Time

In the Figure 4 the comparison of Standard Error by varying weights of parameters is presented for the TOPSIS with Fuzzy AHP weights method. The accuracy of TOPSIS Fuzzy AHP method is measured in terms of Standard Error. The original Fuzzy AHP weights and two sets of random weights are considered. It can be observed that TOPSIS with Fuzzy AHP weights gives the minimum Standard Error \% and is the most effective way for Water Quality Assessment. Hence, the weights calculated using Fuzzy AHP are more appropriate than the random considered weights. 


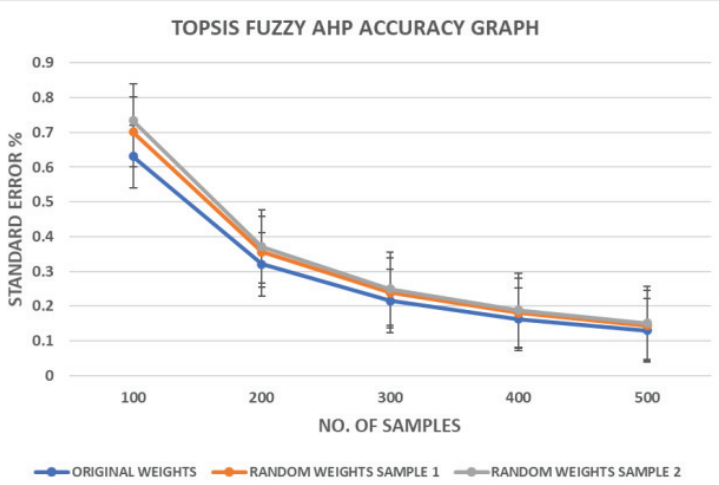

Fig. 4. Comparison of Standard Error by varying weights of Parameters

The Figure 5 shows the comparison of final score assigned for different water samples belonging to various quality levels. The results of all four methods i.e., TOPSIS with Fuzzy AHP weights, TOPSIS with AHP weights, standard Fuzzy AHP and manual assignment is considered for this comparison. The Figure 5 indicates that the score assigned by standard Fuzzy AHP method are quite overestimated as compared to other three methods. Also, the scores of manual assignment method are quite similar to TOPSIS with fuzzy AHP weights approach and hence it can be concluded that this method computes the scores in appropriate manner.

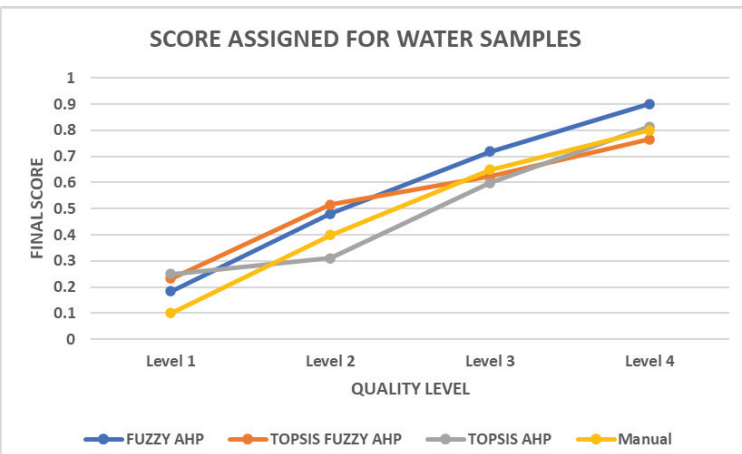

Fig. 5. Comparison of final score assigned for different water samples belonging to various quality levels

\section{Conclusion}

The system to monitor the quality of water on the basis of different parameters is proposed in this paper. The considered water parameters are Arsenic, Ammonia, Iron, Nitrate, Dissolved Oxygen \& Ph. The proposed system applies a Fuzzy- AHP and AHP method to compute weights for these parameters. The priorities of these parameters are taken into consideration while calculating weights. The proposed system also applies the TOPSIS algorithm to assign quality levels to the water samples and the weights computed by Fuzzy-AHP are used during this process. The results show that the TOPSIS with FuzzyAHP weights approach is more accurate for assigning quality levels to water samples. The accuracy is majored in terms of standard error and standard error is less for
TOPSIS method as compared to only Fuzzy-AHP method. The performance analysis of TOPSIS with random weights is also carried out. Here also the TOPSIS with Fuzzy AHP weights outperforms the method with random weights. Thus, the generated weights are appropriate and give better performance while evaluating quality levels to water samples. In future the proposed method can be improved by using any machine learning technique and considering other parameters of water.

\section{References}

1. H. Minh, R. Avtar, P. Kumar, Dat Q. Tran, T.Van, H. Behera, M. Kurasaki, Groundwater Quality Assessment Using Fuzzy-AHP in An Giang Province of Vietnam (2019)

2. Y. Tu, K. Chen, H.Wang, Z. Li , Regional Water Resources Security Evaluation Based on a Hybrid Fuzzy BWM-TOPSIS Method (2020)

3. Arsenic in Drinking Water (2019)

https://www.health.state.mn.us/communities/enviro nment/water/contaminants/arsenic.html\#HeatlhEffe cts

4. $\quad$ Arsenic In Well Water(2019)

https://www.michigan.gov/documents/deq/deq-wdgws-wcu-arsenicwellwater 270592 7.pdf

5. Oregon Department of Human Services, Health Effects Information (2020)

https://www.oregon.gov/oha/PH/HealthyEnvironm ents/DrinkingWater/Monitoring/Documents/health/ ammonia.pdf

6. Insights Editor, Spike in ammonia levels in Yamuna (2020)

https://www.insightsonindia.com/2020/11/03/spike -in-ammonia-levels-in-yamuna/

7. Passaic Bergen Water Softening, Passaic Bergen Water Softening (2017)

https://www.pbwatersoftening.com/5-harmfuleffects-high-levels-iron-water/

8. Iron in Drinking Water (2017) https://dnr.wi.gov/files/pdf/pubs/dg/dg0035.pdf

9. Nitrate in Drinking Water (2019) https://www.health.state.mn.us/communities/enviro nment/water/contaminants/nitrate.html\#HealthEffe cts

10. Frequently Asked Questions About Nitrates and Drinking Water (2018)

https://www.cdc.gov/healthywater/emergency/dwacomm-toolbox/before/tools/FAQ-nitrates.docx

11. Vital Signs:The Five Basic Water Quality Parameters (2018)

https://www.arroyoseco.org/wqparameters.htm

12. Dissolved Oxygen (DO)(2016)

https://www.enr.gov.nt.ca/sites/enr/files/dissolved oxygen.pdfA: : :text $=$ Healthy $\% 20$ water $\% 20$ should $\%$ 20 generally $\% 20$ have, between $\% 20$ about $\% 2080 \% 2$ D120\%20\%25

13. Eldorado Natural Spring Water, Why Is the pH Of Your Water So Darn Important? (2016) 
https://www.eldoradosprings.com/blog/water-andhealth-0

14. Dr J. Cotruvo, Mr J.K. Fawell, Ms M. Giddings, Mr P. Jackson, Prof. Y. Magara, Dr E. Ohanian, $p H$ in Drinking-water (2007)

15. J. Gao, H. He, Q. An, J. Xie, Y. Cui, X. Xie, An Improved Fuzzy Analytic Hierarchy Process for the Allocation of Water Rights to Industries in Northeast China (2020)

16. Z. Chen, H. Zhang, M. Liao, Integration MultiModel to Evaluate the Impact of Surface Water Quality on City Sustainability: A Case from Maanshan City in China (2019)

17. Md. M. Haque, M. Alam, L.Carpenter-Boggs, Sustainability of Water Quality and Ecology(2017)

18. G. Banerjee, Water Quality Value Of Ground Water Treatment Scheme (2016)

19. J. Salman, Assessment Of Water Quality Of Hilla River For Drinking Water Purpose By Canadian Index (CCME WQI) (2015)

20. M. Rabbi, J. Hossen, M. D. Sarwar, P. Roy, S. Shaheed, M. Hasan, Investigation of Waste Water Quality Parameters Discharged from Textile Manufacturing Industries of Bangladesh (2018) 